\title{
"Video-assisted anal fistula treatment (VAAFT): a novel sphincter-saving procedure to repair complex anal fistulas" by Piercarlo Meinero and Lorenzo Mori
}

\author{
Andrew P. Zbar
}

Published online: 21 October 2011

(C) Springer-Verlag 2011

Sir,

It is pleasing to see Dr. Meinero's pioneering work on fistulosocopy finally presented, where he and his colleague Dr. Mori have shown high primary short-term healing rates for a range of simple and complex fistulae-in-ano [1]. The recent trend for complicated and recurrent fistula treatment has been away from formal endoanal procedures such as the mucosal advancement anoplasty, toward more minimalist approaches that disconnect the fistula from its origin or which try to chemically destroy the fistula or exploit its granulation tissue as a scaffold for reparative healing. The rise of any new procedure for repair of an age-old problem like fistula-in-ano to some extent comes about from dissatisfaction either with the outcomes of its technical rivals or from problems with their inherent philosophical approach. In the case of mucosal advancement anoplasty, there is an accepted moderate rate of recurrence which is accompanied by a relatively high incidence of suture-line dehiscence, (which is somewhat operator-dependent), coupled with the technical difficulties involved in its repetition particularly where there is anal canal distortion and where further recurrences correlate with the number of failed previous repairs $[2,3]$. The chemical ablation of fistulae-in-ano and the use of scaffold plugs, although creating an initial excitement, do not appear to live up to their early reputations, where it is unclear how much their failure impairs subsequent definitive repair $[4,5]$. The LIFT procedure appears to be the main rival for VAAFT as it marries minimalism in fistula surgery with initial high

\footnotetext{
A. P. Zbar $(\bowtie)$

Department of Surgery and Transplantation, Chaim Sheba Medical Center, Tel Aviv, Israel e-mail: apzbar1355@yahoo.com
}

success rates. LIFT takes note of the old observation that secondary fistula tracks will heal if they are disconnected from the principal fistula which itself is setonized, excised or repaired. Such an observation changed the management of extensive horseshoe ischiorectal abscesses in the 1980s from those large festering ischiorectal wounds that one would frequently see as a resident to the incision/counterincision procedures which would rapidly heal in most patients without incident [6]. The minimalist approach offered by VAAFT requires validation in complicated perianal Crohn's disease but it would appear that its potential value makes intuitive sense in the absence of available prospective data. What its place might be in selected rectovaginal fistula management as an ancillary to definitive repair also remains to be seen. One of the limitations of VAAFT is that it cannot be used in the absence of an external opening, as sometimes happens with chronic fistulae. Also, it may well be that some circuitous and iatrogenic fistulae are less suited to the passage of a straight videoscope, where the same criticism could be leveled at the use of alternatives such as the recently described radial emitting laser probe for fistula management [7]. The intersphincteric route of the fistula track which is somewhat poorly defined on advanced imaging still needs to be accurately delineated by the operator in the creation of the staple "volcano" as Meneiro has described [8].

It would appear that the philosophy of the LIFT and the VAAFT will be acknowledged if their long-term outcomes prove acceptable, but also because they are both unlikely to substantially compromise further attempts at definitive repair and because they preserve sphincter muscle and function [9]. Again, although we do not have prospective functional, manometric or quality of life data (as it pertains to fistula surgery) and as yet cannot comment on costeffectiveness of the procedure as a standard for fistula cure, 
it would also seem intuitive that this philosophical shift in fistula management is probably to the patient's advantage. Put simply, if there is sustainable success, the more minimalist the surgery the better the outcome. VAAFT as part of the proctological armamentarium is still in my opinion going to be something that is selectively used, but it has many attractions.

Conflict of interest The author has declared that no conflict of interest exists.

\section{References}

1. Meinero P, Mori L (2011) Video assisted anal fistula treatment (VAAFT): a novel sphincter-saving procedure to repair complex anal fistulas. Tech Coloproctol 15 (in press)

2. Mizrahi N, Wexner SD, Zmora O et al (2002) Endorectal advancement flap: are there predictors of failure? Dis Colon Rectum 45:16-21
3. Abbas MA, Lemus-Rangel R, Hamadani A (2008) Long-term outcome of endorectal advancement flap for complex anorectal fistuae. Am Surg 74:921-924

4. Haim N, Neufeld D, Ziv Y et al (2011) Long-term results of fibrin glue treatment for cryptogenic perianal fistulas: a multicenter study. Dis Colon Rectum 54:1279-1283

5. Dudukgian H, Abcarian H (2011) Why do we have so much trouble treating anal fistula? World J Gastroenterol 17:32923296

6. Held D, Khubchandani I, Sheets J, Stasik J, Rosen L, Riether R (1996) Management of anorectal horseshoe abscess and fistula. Dis Colon Rectum 29:793-797

7. Wilhelm A (2011) A new technique for sphincter-preserving anal fistula repair using a novel radial emitting laser probe. Tech Coloproctol (in press)

8. Buchanan GN, Williams AB, Bartram CI, Halligan S, Nicholls RJ, Cohen CR (2003) Potential clincial implications of direction of a trans-sphincteric anal fistula track. Br J Surg 90:1250-1255

9. Zbar AP, Khaikin M (2011) Should we care about the internal anal sphincter? Dis Colon Rectum (in press) 